\title{
periferio:
}

\section{BICHAS DESTRUIDORAS MESMO: CONSTRUINDO UMA VIADA BEM AFEMINADA}

\author{
Anderson Cacilhas Santiago ${ }^{1}$ \\ Universidade Federal do Espírito Santo - UFES \\ Naiara Ferreira Vieira Castello ${ }^{2}$ \\ Universidade Federal do Espírito Santo - UFES \\ Alexsandro Rodrigues ${ }^{3}$ \\ Universidade Federal do Espírito Santo - UFES
}

\section{Resumo}

Este artigo busca desenvolver uma discussão analítica e crítica acerca da produção da identidade afeminada, a partir de dois vídeos e um filme documentário, publicados na internet: "Gays afeminados"; "Lázaro, 22"; e "Bichas, o documentário". Essas produções audiovisuais contestam o lugar de abjeto destinado aos gays afeminados, retomando-os como potência transformadora. Junto às teóricas e aos teóricos queer, dos estudos culturais, feministas, pós-estruturalistas e da comunicação social, neste artigo busca-se questionar o caráter ofensivo que se atribui à feminilidade nas relações estabelecidas entre as bichas e na militância LGBT e a tentativa de extinguir o que é culturalmente classificado como feminino da construção dos corpos e das identidades. Acredita-se que tais vídeos, sobretudo a partir do momento em que extrapolam o ambiente da internet e influenciam o agendamento da grande mídia, tornam-se ferramentas de transformação do modelo de dominação masculinista, inclusive do ideal de masculinidade hegemônica e da heteronormatividade afirmados pelas próprias bichas.

Palavras-chave: gays afeminados; heteronormatividade; identidade

\footnotetext{
${ }^{1}$ Mestrando do Programa de Pós-Graduação em Psicologia Institucional - UFES. ocacilhas@gmail.com

2 Mestranda do Programa de Pós-Graduação em Psicologia Institucional - UFES. naiaracastello@gmail.com

${ }^{3}$ Professor do Programa de Pós-Graduação em Psicologia Institucional - UFES. xela_alex@bol.com.br
} 


\title{
periferio
}

\section{TRULY FIERCE FAIRIES: CONSTRUCTING A VERY EFFEMINATE QUEEN}

\begin{abstract}
This paper seeks to develop a critical and analytical discussion on the production of the effeminate identity, using two videos and a documentary film published in the internet: 'Gays Afeminados' ("effeminate gay men"); 'Lázaro, 22'; and 'Bichas, o documentário' (“Fairy, the documentary”). These audiovisual productions contest the abject place destined to effeminate gay men, reinstalling them as a transformative potency. Along with queer theoreticians, cultural studies, feminist studies, post-structuralism and social communication, this paper questions the offensive character attributed to femininity in the relations established between queens and in the LGBT movement, and the attempt to extinguish what is culturally labeled as feminine from the construction of the bodies and identities. Such videos, especially when they extrapolate the scope of the internet and influence mass media, become tools for the transformation of the masculine domination model, including the ideal of hegemonic masculinity and heteronormativity asserted by the queens themselves.
\end{abstract}

Keywords: effeminate gays; heteronormativity; identity. 


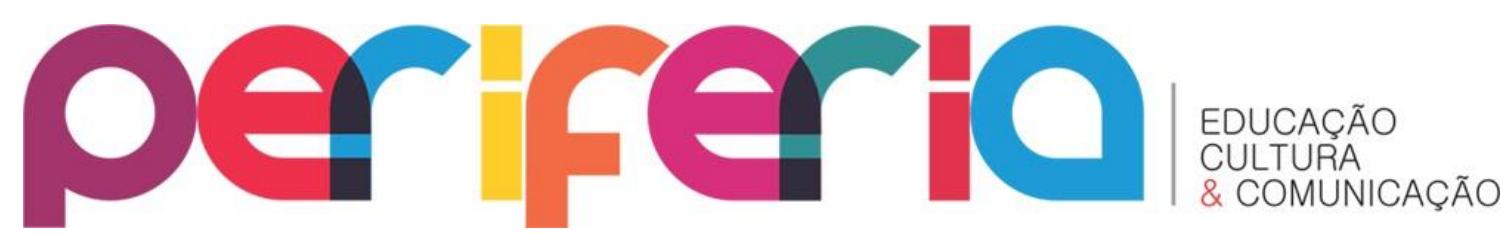

INTRODUÇÃO: "ISSO É UMA BICHONA"4

Põe a cara no Sol, mona. Põe a cara no Sol, querida. Aceita, gay. É pra poucas a cara no Sol, mona. Bicha bonita não se esconde. Mostra o rosto, a feminilidade (MARTORY, 2015).

Já dizia a participante Sangalo, no reality show Glitter - em busca de um sonho, ao ser confrontada por Rochele Santrelly, sua adversária no programa: “bicha, a senhora é destruidora mesmo”. Pensamos, com ela, no caráter político do termo "bicha”, uma vez que "não é suficiente afirmar que a política está na vida cotidiana. É mais exato afirmar que ela é a vida cotidiana. É a política que tece as relações sociais banais, insignificantes, públicas ou privadas, de dia e de noite” (LOURAU, 2004, grifos do autor). A proposta, portanto, ao utilizarmos tal termo - historicamente considerado pejorativo -, não é menosprezar as sexualidades ditas dissidentes. Ao contrário, buscamos potencializá-las, a partir do reconhecimento da torção que se produz no sentido da palavra quando do seu uso cotidiano pelas próprias bichas.

Da cacura à barbie, das bears às pintosas ${ }^{5}$, as categorias multiplicam-se indefinidamente e, ainda assim, não dão conta da multiplicidade dos modos de ser bicha e de suas singularidades. Longe de caberem nessas categorizações, as bichas afirmam-se na diferença - afinal, a identidade é sempre escorregadia, escapando ao seu próprio propósito de homogeneização

\footnotetext{
${ }^{4}$ Bordão do personagem Severino Quebra-Galho, do extinto Zorra Total, programa de sábado à noite da Rede Globo que foi substituído pelo Zorra, que mudou o elenco e aboliu bordões como o "Isso é uma bichona". O personagem, interpretado pelo ator Paulo Silvino, substituía alguém ou algum objeto em falta num set de filmagens. Quando Ihe mostravam os gestos que teria que reproduzir no set, que remetiam a trejeitos afeminados, Severino gritava: "Isso é uma bichona". Apesar do fim do quadro, o bordão de Severino ainda é amplamente conhecido e foi assistido por milhões de pessoas durante anos. Alguns desses momentos podem ser vistos no seguinte link: <www.youtube.com/watch?v= 9R 3YON9LOY>.

${ }^{5}$ Categorias utilizadas pelas bichas, classificando a si mesmas e às outras a partir de características físicas e comportamentais compartilhadas. A partir das definições trazidas pela página Dicionário Informal, onde os leitores contribuem com as definições das palavras, cacura são as bichas mais velhas; as barbies são as da academia, que adoram se exibir; as bears são as peludas e corpulentas, lembrando a aparência de um urso; e as pintosas são as que gostam de dar pinta, de aparecer.
} 


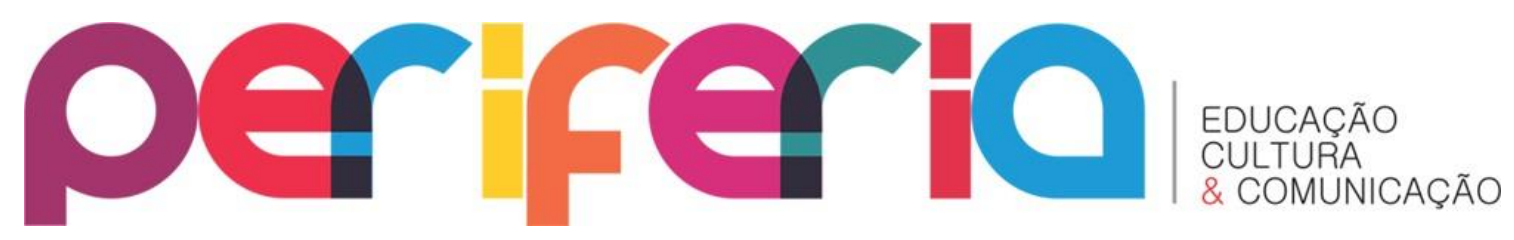

e à estereotipização. As posições ocupadas pelos sujeitos são multidimensionais e se modificam a partir de outras conexões de contextos, espaços e tempos (HALL, 2003). Se consideramos a identidade como performatividade - categoria política forjada numa repetição de si que falha constantemente e, falhando, produz novidade (BUTLER, 1993) -, a bicha não é uma posição estanque, mas uma experiência que se reinventa a todo tempo. As relações entre identidades e sexualidades, nessa produção constante, são mediadas, ainda, pelos significados compartilhados culturalmente a respeito das sexualidades e por sistemas de representação que recortam quais condutas devem ser mais valorizadas do que outras (WOODWARD, 2014).

As instituições que atualizam e reproduzem esses significados (a religião, a Medicina, o Direito, a Psiquiatria, a Psicologia, dentre outras) produzem discursos acerca do sexo que se empenham não apenas em classificar os tipos de sexualidades existentes, mas também em ampliar os modos de controlá-las de forma efetiva, impondo a heteronormatividade a todo instante, inclusive no meio gay. Por meio de um processo de normalização, atribuem-se a uma identidade, eleita como modelo, características avaliadas socialmente como positivas, relegando as outras, por oposição, a um polo negativo (SILVA, 2014). Paradoxalmente, a existência de uma matriz que tenta delimitar os padrões das bichas abre caminho para que as transgressões ocorram (LOURO, 2004).

0 enquadramento é uma interpretação de fatores que regem o mundo, estruturando uma imagem mediante relação de produção de verdades, subjetividades, processos e vidas (BUTLER, 2015). Mas, como as afeminadas nos mostram, os quadros sempre vazam de suas bordas, fugindo de molduras que nunca contiveram de fato a cena que a heteronormatividade se propunha a ilustrar. É assim que se produzem cotidianamente as figuras abjetas, que escapam aos processos de normalização.

Esboçando uma breve genealogia do movimento LGBT no Brasil, percebemos uma tentativa de rechaçar a bicha afeminada, taxando-a de mero produto e reprodutora dos padrões homossexuais e dos papeis de gênero, em 


\section{periferio}

contraste com o homossexual, figura calcada na respeitabilidade, que seria o sujeito da militância por excelência. Peter Fry (1982) demonstra uma sucessão de sistemas de representação, que passa, a partir da década de 1960, da relação homem/bicha, supostamente hierarquizada quanto aos papeis de gênero, à relação presumidamente simétrica entre homossexuais, condensada na figura do "entendido", que não se classifica como masculino/feminino ou ativo/passivo. Essa transição teria se operado com a mediação de modelos médicos, psicológicos e psicanalíticos.

Fry afirma que, a partir da década de 1970, com a organização dos primeiros grupos de militância em torno da homossexualidade, que chamaremos aqui de "movimento homossexual"6, o termo "bicha" é retomado, mas esvaziado de seu sentido pejorativo. Guido Mantega, no livro Sexo e poder, apresenta a fala de um militante do Somos, reconhecido como o primeiro grupo de militância homossexual do Brasil, em 1979, criticando o lugar do que chama de "bicha pintosa":

É que o próprio homossexual está muito pouco esclarecido a respeito da sua homossexualidade, tanto assim que reproduz, na prática, os padrões heterossexuais, caricaturando as funções de atividade e passividade, por exemplo. Existe sempre aquela "bicha pintosa", "desmunhecada", à procura do seu "bofe", isto é, daquele que vai exercer o papel masculino na relação. Isso é muito falso, pois não tem nada a ver com a homossexualidade em si (MANTEGA, 1979).

Também Edward MacRae, ao discutir a experiência de implementação de uma "editoria homossexual" num jornal alternativo de São Paulo, criado em função da construção do Partido dos Trabalhadores, entre 1980 e 1981, aponta para uma tentativa de neutralização da militância homossexual, com o

\footnotetext{
${ }^{6}$ Utilizaremos as expressões "movimento homossexual" e "militância homossexual" em referência aos primeiros movimentos de militância organizados em torno da sexualidade no Brasil, de acordo com a forma como os próprios grupos se denominavam e em consonância com a literatura (eg. FACCHINI, 2003).
} 


\title{
periferio
}

objetivo de adequá-la às táticas e estratégias da militância socialista, principalmente por meio da modulação do vocabulário:

\begin{abstract}
Alegava-se que a linguagem usada era apropriada a uma publicação voltada a um mercado guei, mas que naquele jornal ela serviria somente para confirmar preconceitos, reforçando a imagem caricatural do homossexual [...] Para serem ouvidos e entendidos, pediam-lhes que higienizassem a homossexualidade, reduzindo seus praticantes à categoria mais facilmente assimilável de "grupo oprimido lutando por seus direitos" (MACRAE, 2011).
\end{abstract}

$\mathrm{O}$ autor segue afirmando que a postura adotada pelo corpo editorial não diferia do posicionamento geral da militância homossexual, à época. Ao reivindicarem o reconhecimento de que "poderiam ser cidadãos tão bons, decentes e integrados quanto os heterossexuais" (MACRAE, 2011, p. 25), a partir de uma concepção da homossexualidade como tendência natural e congênita, os militantes marcavam, por outro lado, sua diferença daqueles que seriam considerados "degenerados", cuja homossexualidade seria "adquirida" e estaria sujeita a repressão e punição. Diferença sintetizada no título do artigo: "Os respeitáveis militantes e as bichas loucas".

$\mathrm{Na}$ continuidade, MacRae comenta os processos de militância pela "desmunhecação" e pelo escândalo, que se insurgem nos Estados Unidos e na Europa, a partir de formação da Gay Liberation Front, em Nova York, em 1969, em oposição à militância naturalista e higienista que havia se forjado nas décadas anteriores. Esses novos movimentos aderiam aos comportamentos estereotipados, chegando até ao travestismo, como tática de enfrentamento à estigmatização, ainda em embate com um modo de fazer militância calcado na afirmação da respeitabilidade.

Passado, contudo, o primeiro período documentado do movimento homossexual no Brasil (que compreende a segunda metade da década de 1970 e o início da década de 1980), com o processo de reabertura política após a ditadura militar e o surgimento da aids, Néstor Perlongher (1993) discorre sobre um "desaparecimento da homossexualidade", que se dá de forma 


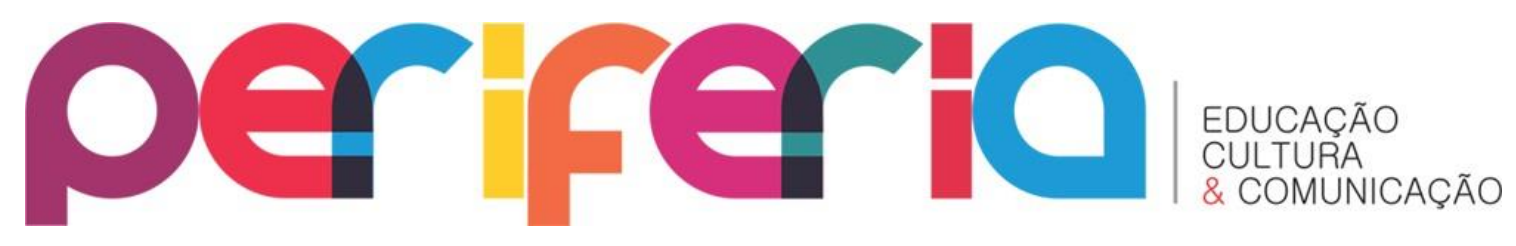

discreta, quase imperceptível, mediante a medicalização, normalização e, por fim, banalização da experiência homossexual, cujas marcas se espalham pelo corpo social e perdem, assim, suas singularidades. Fala-se de um declínio do movimento LGBT, de um modo geral, nesse período, até a década de 1990, quando volta mais institucionalizado, com acesso às mídias, participação em movimentos formais de direitos humanos, vinculações a redes internacionais e condução de ações junto a parlamentares (FACCHINI, 2003).

Gostaríamos de afirmar a potência dessa "bicha pintosa", afeminada, desmunhecada, que fora esvaziada de sentido político no início da militância LGBT no Brasil, apagada no início da epidemia da aids e capturada pelas instituições e pelas políticas públicas a partir da década de 1990. Apostamos na bicha como a possibilidade de construção de outro senso de realidade para si e para o mundo - que não é apreensível pelos quadros representacionais que julgam conhecer e compreender uma realidade supostamente estanque. Para as bichas, "o que importa é o andar e não o chegar. Não há um lugar de chegar, não há destino pré-fixado, o que interessa é o movimento e as mudanças que se dão ao longo do trajeto" (LOURO, 2004, p. 13). Só o movimento equilibra as afeminadas, mas, na lógica ocidental em que nos encontramos inseridos, buscamos uma explicação exacerbada e um enquadramento rígido de acontecimentos e realidades. A partir da regulação de nossas práticas, por meio de produção de recortes binários, fixamos um tipo modelar de sujeito que determina o outro por oposição, inferiorizando-o e subordinando-o.

Desmontando o binarismo de gênero em que somos enredados, a afeminada é a demonstração de que o gênero e a sexualidade são performáticos. Butler (2003) nos diz que o gênero é constituído socialmente por sujeitos que produzem um ponto relativo, em que convergem práticas culturais e histórias capazes de delimitar os lugares ocupados pelas masculinidades e feminilidades em nossa sociedade. Somos interpelados constantemente pelos modos de ser homem e mulher, que replicamos e performamos cotidianamente e que se naturalizam nos nossos corpos 


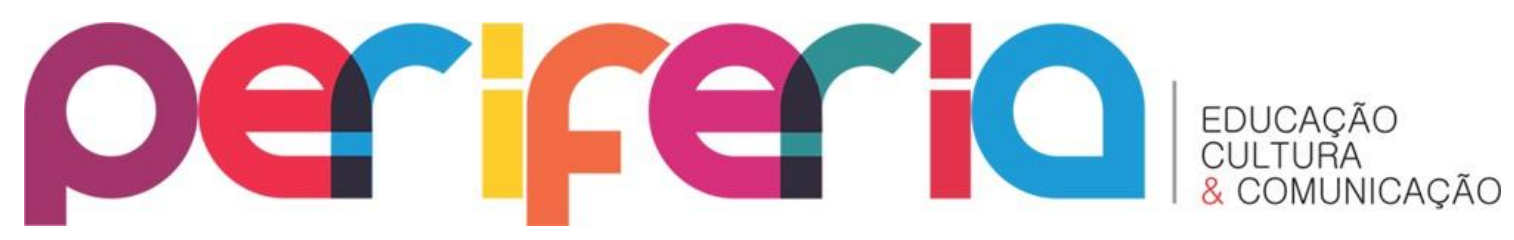

máquinas que não são determinadas pelo biológico, mas produzidas socialmente. O significado político do reconhecimento do sexo enquanto ato performático é produzido e reproduzido pelas nossas repetições cotidianas.

É nesse sentido que vale pensar nas formas como os corpos afeminados resistem aos vários processos biopolíticos e disciplinares que os perpassam, constituindo condições outras de ser e estar no mundo e criando guerras que se dão por outros meios em nosso cotidiano. Zamora (2008) nos indaga quais são as possibilidades de resistência que criamos nos corpos, que instauram ativamente modos de viver mais vibrantes: "quais as possibilidades de resistência dos corpos bucólicos, dos corpos da vida de gado? Como deixar que outras forças do mundo nos atravessem?” (ZAMORA, 2008, p. 113). Sem deixar respostas para essas indagações, a autora nos instiga a pensar nas resistências como potências na produção de outros possíveis, demarcadores de espaços nunca antes navegados e produtores de novas subjetividades que se fazem com o corpo.

Articulando os questionamentos de Zamora com Butler, para quem "o corpo está exposto a forças articuladas social e politicamente, bem como a exigências de sociabilidade - incluindo a linguagem, o trabalho e o desejo" (BUTLER, 2015, p. 15-16), pensamos a potência plástica do corpo afeminado e seus cortejos com os estudos e as políticas queer. Queer são modos de ser que não desejam, necessariamente, produzir referências; são viveres que desafiam as normas regulatórias dos corpos e da sociedade, assumindo, no desconforto do seu existir, um espaço de produção (LOURO, 2004). Por oposição às políticas identitárias/essencialistas, os corpos afeminados também são afetados por identidades, mas vão de encontro àqueles que se autodenominam como "normais".

Manipular um corpo queer é enfrentar os pensamentos heteronormativos, que se dizem hegemônicos, universais, "normais", mas temem os efeitos das multidões abjetas que eles mesmos criaram. As multidões queer surgem como uma posição crítica dos efeitos normalizantes e disciplinares da formação identitária, recusando uma ontologia dos sujeitos e 


\section{periferio}

das políticas. Nesse sentido, é possível afirmar que não há uma base natural comum à posição de mulher ou de gay, por exemplo, já que cada uma dessas identidades refere-se a uma multidão de diferenças, uma transversalidade de relações de poder e a uma diversidade de potências de vida (PRECIADO, 2011). É nessas diferenças que são criados os verdadeiros monstros sociais, aos modos do Frankenstein, de Mary Shelley, que colocam em questão os regimes representacionais e os sistemas de produção de saberes que regem nossa sociedade. Assim, o biopoder passa pelo corpo afeminado criando uma bioresistência afeminada que diz para o mundo: "não, obrigado".

Os monstros de nossa sociedade são aqueles que evidenciam uma forte riqueza emocional e uma capacidade de sentimentos que aqueles tidos como normais não conseguem captar. Nessa configuração, o humano é aquilo que age como um aleijado emocional: frios e sem coração, preferem distância do outro que pode the ensinar algo de diferente, possível, enriquecedor aos modos do viver (HARDT; NEGRI, 2005). Dessa forma, as afeminadas querem apenas ser amadas em suas diferenças, mas parece que as outras bichas não as entendem e preferem manter-se em seus espaços de conforto. A diferença atrapalha, incomoda e precisa ser varrida para debaixo do tapete, para manter a desordem da ordem mundial bicha.

Partindo dessas análises, buscamos com este texto discutir a produção da experiência da bicha afeminada a partir de três vídeos publicados na internet: "Gays Afeminados"7, presente no canal do Youtube intitulado "Para Tudo, de Lorelay Fox"; "Lázaro, 22"8, sobre Lázaro dos Anjos Moreira, na página do Vimeo do projeto Los Chicos; além do documentário "Bichas - o documentário", que dá voz a seis bichas que relatam suas experiências de empoderamento ao se descobrirem e se afirmarem como tal. São vídeos que contestam esse lugar de abjeto destinado aos afeminados, discutindo várias

\footnotetext{
${ }^{7}$ Até o momento do acesso havia sido visualizado 131.615 vezes.

${ }^{8}$ Até o momento do acesso havia sido curtido 3.539 e compartilhado 1.691 vezes.

${ }^{9}$ Até o momento do acesso havia sido visualizado 659.049 e comentado 3569.
} 


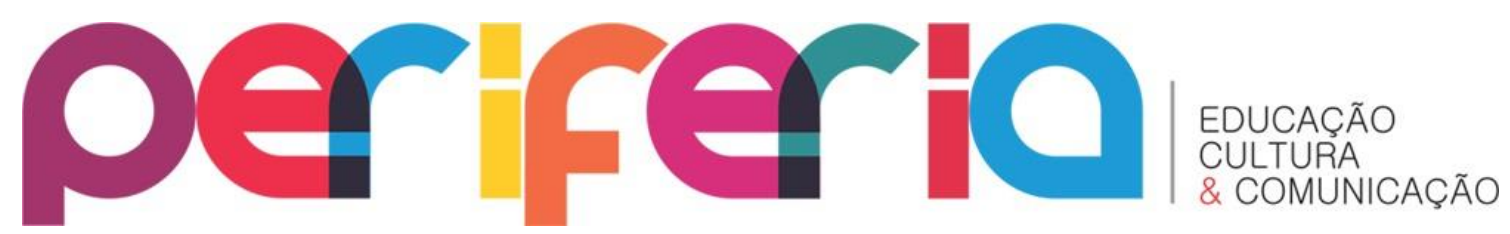

questões que as atravessam de alguma forma, como a heteronormatividade, os gays machistas, discriminação, violência e desejos sexuais.

\section{"VOCÊ É A MAIS AFEMINADA DO GRUPO"10: CONHECENDO AS PINTOSAS DA INTERNET}

Quem nunca ouviu dizer "tudo bem você ser gay, mas não seja uma bichona afeminada"? A gente até espera ouvir isso dos héteros, mas é assustador ver esse discurso se repetir muito e principalmente no próprio meio gay. Um lugar onde nós devíamos nos sentir acolhidos, sendo aceitos por quem a gente é. Ao invés disso, continuam querendo que nós (gays) nos comportemos como os outros, seguindo uma norma hétero e desqualificando as pessoas que minimamente fogem desse padrão (GAYS, 2015).

Observamos, em nossa sociedade, uma rejeição às afeminadas, que se agrava ao pensarmos que ela também ocorre entre os próprios gays, que valorizam os sujeitos que conseguem imprimir uma masculinidade e virilidade mais próxima à dos denominados/classificados homens hétero e cissexuais. São os que se denominam "machos" e "discretos”, em oposição às afeminadas e pintosas, que constroem dicotomias em que o primeiro polo é o valorizado positivamente. Nesse processo relacional entre os próprios gays, a masculinidade serve de salvo conduto para que o oprimido se transforme em opressor.

Podemos intuir que, quando esses homens se dizem "machos", não estão se opondo necessariamente apenas à feminilidade. Na realidade, opõem-se também a uma feminilidade específica: a da bicha, da efeminação (BRAZ, 2010). Assim, a rejeição poderá ocorrer a partir de quaisquer atributos - corporais, gestuais, comportamentais ou emocionais - que possam ser relacionados tanto ao estereótipo da bicha, em seu exagero, quanto ao que é comumente atribuído ao lugar da mulher. Igor Ferreira foi vítima dessa oposição dos “machos” à efeminação:

10 Trecho do programa 220 Voltz, do canal Multishow, protagonizado pelo ator Paulo Gustavo. Disponível em: <https://www.youtube.com/watch?v=s Ey7mi2Ov0>. 


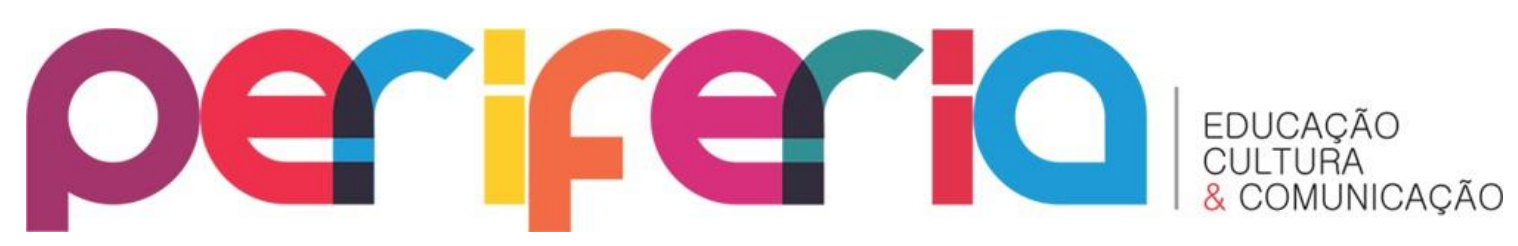

Foi Hannah Montana se tornando Miley Cyrus ${ }^{11}$ [...]. Queriam me zoar e me xingar de bicha, de gay, de viado, o que fosse. $\mathrm{E}$ eu não queria aqueles adjetivos ligados a mim. $E$ aí eu passei a odiar o que aquilo era. Passei a odiar o que a bicha era [...]. Fazer do ser bicha algo tão importante e tão grandioso quanto realmente é. [...] você vai ter que me aceitar e você vai ter que gostar e uma hora se você estiver muito incomodada com isso eu não posso fazer nada porque eu estou ótima querida! Eu tô perfeita sendo bicha! Eu amo ser bicha! (BICHAS, 2016).

0 rechaço aos atributos associados à efeminação implica uma reiteração das hierarquizações baseadas no gênero, valorizando o masculino em detrimento do feminino. Bourdieu (2000) denomina "dominação masculina" como uma violência simbólica, insensível e invisível às suas vítimas e que é tomada como uma arbitrariedade cultural e natural ao mesmo tempo. O autor afirma, ainda, que a justificativa da legitimação dessa dominação masculina é ancorada em uma natureza biológica que é em si mesma uma construção social naturalizada. Ou seja, é através da naturalização das dissimetrias de gênero que se faz da dominação masculina algo aparentemente universal, inevitável e necessário. Destacamos que a busca por uma naturalização é sempre uma estratégia de poder, que objetiva a manutenção de relações de dominação - tanto material, quanto simbólica.

Existe uma performance repetida continuamente e cotidianamente pelos homens - seja pelos gays ou pelos heterossexuais - para alcançarem um modelo ideal e social de masculinidade que, na realidade, é impossível de se atingir. Nessa repetição performativa (BUTLER, 2003), criam-se sempre cópias imperfeitas dos modelos que se buscam. Esse processo ocorre sob uma vigilância constante, pois necessita da aprovação por parte de outros homens, para se manter e ser validado. "Em vez de ser obtida automaticamente, a

11 Miley Cyrus é uma cantora pop americana que ficou mundialmente famosa por atuar na série infantojuvenil "Hannah Montana", da Disney. De acordo com o Portal Terra, em sua sessão Babadice, em 2013 ela subiu ao palco do Video Music Awards (VMA), principal prêmio de clipes da MTV americana, e surpreendeu os fãs e o mundo da música pop. Ela usava um biquíni cor da pele, maiô de ursinho, e executava uma coreografia cheia de referências sexuais com a língua de fora. Polêmica, atirada, provocante, ousada e despreocupada, a Miley de hoje é um retrato muito distante da Miley meiga e delicada de antigamente. 


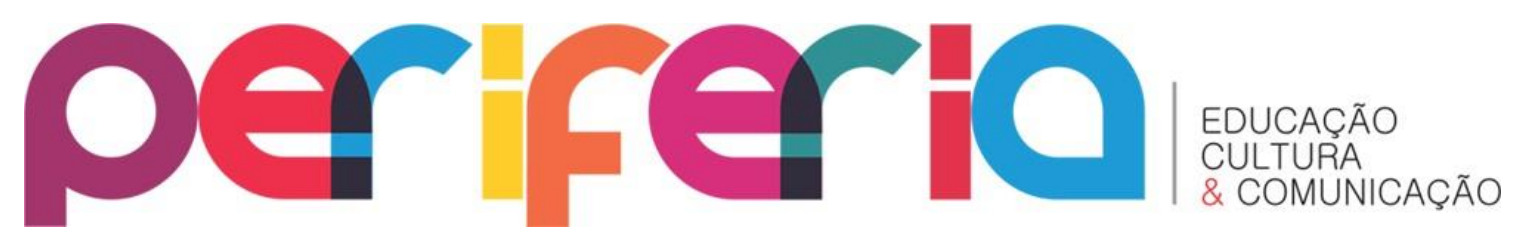

virilidade deve ser construída, digamos, fabricada. O homem é, portanto, uma espécie de artefato e, como tal, ele corre sempre o risco de ser defeituoso" (BADINTER, 1992, p. 149). Compreendemos, assim, como a masculinidade é frágil e precisa constantemente se afirmar, por exemplo, no menosprezo do outro não-viril, isto é, das afeminadas e das mulheres. Entretanto, há uma resistência e ressignificação das agressões sofridas, que, aos modos do que se expressa do relato de Ítalo Amorim, funciona como proteção diante da hostilidade desferida contra a sua posição enquanto artefato que não construiu a masculinidade esperada:

Ok querida, eu sou bicha sim. Obrigada. Descobriu o Brasil. E agora? Diz outra coisa aí. Essa não me ofendeu. Eu sou bicha sim. Você pode usar essa arma que apontam pra você de volta [...]. Levantar essa bandeira é o meu grito, é a minha resistência, é a minha proteção. Para mim e para os meus, sabe? (BICHAS, 2016).

Nesse sentido, é preciso pensar nas possibilidades subversivas que poderiam questionar a própria prática reguladora da identidade masculina. Um caminho é a produção de performances que desviem de seus propósitos originais e mobilizam possibilidades de sujeitos "que não apenas ultrapassem os limites da inteligibilidade cultural como efetivamente expandem as fronteiras do que é, de fato, culturalmente inteligível” (BUTLER, 2003, p. 54). Com efeito, esses tipos de "falhas" de identidade de gênero expõem os limites da eficácia e coerência da matriz de inteligibilidade da heteronorma. Isso é o que Lázaro nos aponta:

Todos os gays tinham que ter um padrão, tinham que ser fortes, tinham que tirar a camisa na balada, tinham que ter barba, tinham que ser masculinos. E essas são todas as coisas que eu não sou e definitivamente não quero ser. Eu não sou masculino e eu não vou cortar meu cabelo. É como se eu ser gay afeminado me excluísse de uma série de outras características positivas que um gay masculino tem (LÁZARO, 2015). 


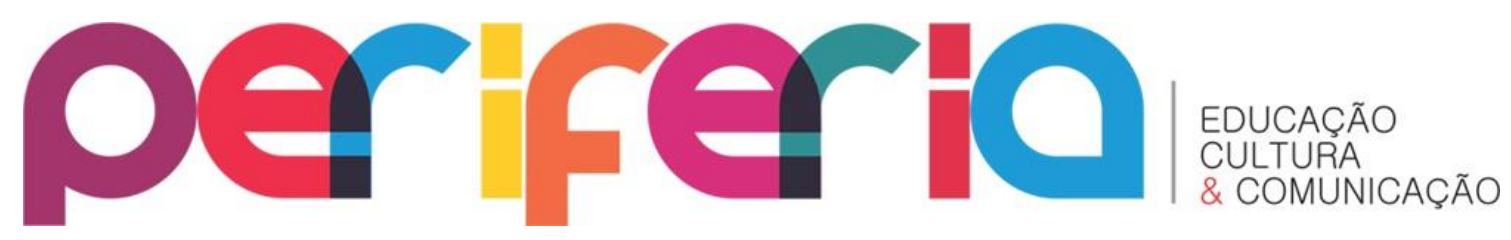

0 discurso afeminado provoca deslocamentos nas configurações de gênero, criando-se fora das estruturas restritivas da dominação masculinista e da heteronormatividade. 0 conceito de heteronormatividade foi criado em 1991 por Michael Warner, com o objetivo de dar conta de uma nova ordem social em que todos - sejam heterossexuais ou não - deveriam organizar suas vidas conforme o modelo heterossexual. "A heteronormatividade é a ordem sexual do presente, fundada no modelo heterossexual, familiar e reprodutivo. Ela se impõe por meio de violências simbólicas e físicas dirigidas principalmente a quem rompe normas de gênero" (MISKOLCI, 2012, p. 44). Orlando Dantas, do filme "Bichas, o documentário", fala desse deslocamento:

Bichas são pessoas transgressoras. É aquela que tá indo contra o padrão, indo contra a maré. [...] As bichas são livres. [...] Se elas quiserem, vão usar um shortinho, uma regata e botar maquiagem na cara. Usar uma saia, usar uma bata, usar um cropped. Elas são apontadas na rua, são motivo de chacota. [...] Se a gente for viver nesse padrão que a sociedade acha que é o certo, a gente não vai ser livre nunca (BICHAS, 2016).

A heteronormatividade supõe a existência de uma relação intrínseca entre o gênero e a materialidade do corpo. Em outras palavras, o gênero depende da natureza e da genitália: se você possui um pênis, logo, deve imprimir em si uma virilidade e ser másculo, pois é preciso manter uma linearidade entre sexo e gênero (BUTLER, 2003).

As pessoas com genitália masculina devem se comportar como machos, másculos, e as com genitália feminina devem ser femininas, delicadas. Nesse sentido, um homem até pode ser homossexual, inclusive fora do armário, mas não pode se identificar com o universo feminino, nem uma mulher lésbica pode se identificar com o masculino (COLLING; NOGUEIRA, 2014, p. 180).

Percebemos, portanto, como a heteronormatividade prescreve um modelo a ser seguido em que as pessoas só se tornam coerentes e inteligíveis desde que se identifiquem com essa normativa. Além disso, podemos 


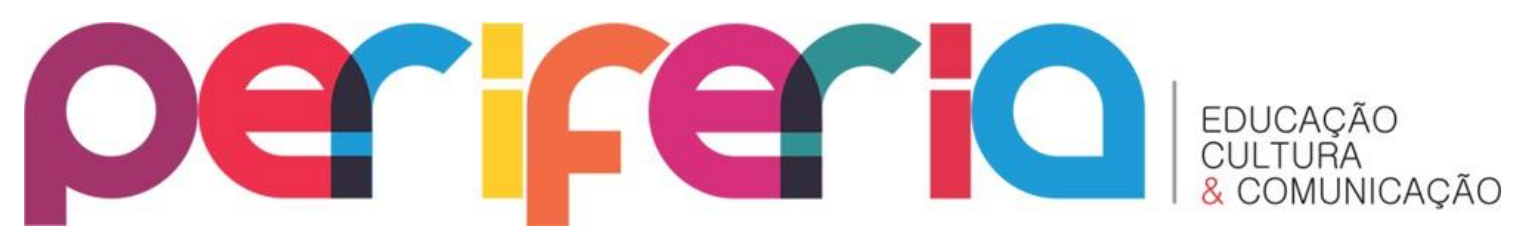

compreender o preconceito que as afeminadas sofrem, já que deveriam, de acordo com esse modelo heteronormativo, identificar-se com o universo masculino. Quando isso não ocorre, sofrem violências físicas e simbólicas. Podemos observar nas palavras de Lázaro como isso se materializa: "Eu me sinto uma pessoa normal, eu acho que eu ser afeminado não é um problema que eu tenho, é um problema que as pessoas têm comigo. Então isso me incomoda. Eu não me sinto triste, eu me sinto subestimado" (LÁZARO, 2015).

Diante da compreensão do mecanismo que sustenta a lógica da heteronormatividade, que convoca a uma necessidade de se manter a linearidade entre sexo e gênero, podemos pensar em modos de questionar e problematizar essa lógica. Se levarmos à frente a separação de sexo e gênero, inscreve-se, então, a possibilidade de "uma descontinuidade radical entre os corpos sexuados e gêneros culturalmente construídos" (BUTLER, 2003, p. 26). Além disso, coloca-se a possibilidade de proliferar e multiplicar o número de gêneros, implodindo os binarismos em que estamos enredados.

Deveríamos invocar o gênero a partir de uma fluidez, distante das dicotomias e dos binarismos nos quais estamos inseridos e que oprimem as possibilidades do vivo. Vale lembrar que o imperativo da linearidade entre sexo e gênero continua sua extensão com o desejo e, ao final, com as identidades sexuais. Nessa relação sexo-gênero, estabelece-se uma cadeia com uma ordem compulsória, imposta e reforçada por diversas instituições, como escola, igreja, mídia, dentre outros. Assim: sexo [pênis/vagina] > gênero [masculino/feminino] > desejo [hétero/homo] > identidades sexuais. Tal linearidade prescreve que temos que ser biologicamente macho ou fêmea e, em seguida, impõe que precisamos incorporar uma identidade de gênero masculina ou feminina e que temos de ter uma orientação sexual para a heterossexualidade. Por último, produz-se uma identificação sexual.

Esse raciocínio articula três questões distintas, em que não há nenhuma razão "natural" para que estas estejam obrigatoriamente associadas. O que se busca, na verdade, é implantar padrões em detrimento da diversidade das experiências vividas. Mas, se rompermos com essa ordem compulsória, abre-se 


\section{periferio}

caminho para uma infinidade de possibilidades de práticas e identidades e para se viver os prazeres do corpo.

As afeminadas borram essas fronteiras impostas, uma vez que possuem, ao mesmo tempo, pênis e atributos do universo feminino. Elas usam saias e cuecas ao mesmo tempo. Passam um lindo batom vermelho, mas não precisam fazer a barba antes de passar a maquiagem. Sentem atração por outros homens e não se denominam mulheres. Em resumo, a afeminada é um caos ambulante que recusa os polos, pois ela não é "isso" ou "aquilo", mas uma mistura de identificações.

Há uma outra questão que surge para ser problematizada em relação a elas: o gênero e a posição na relação sexual, pois é atribuída ao gay afeminado a passividade no momento do sexo. Lázaro Moreira e Lorelay Fox nos falam disso nos seguintes trechos: "Ser passivo, só porque eu sou afeminado: isso não é um pacote. A gente não é feito de pacotes. 0 gay ou qualquer pessoa é feita por etapas. Eu tenho a minha personalidade, o que eu sou na cama, eu tenho minha aparência" (LÁZARO, 2015). "Eu estou falando de ser afeminado, e não de ser passivo ou ativo, porque achar que o afeminado é sempre o passivo também é um preconceito" (GAYS, 2015).

Parece existir em nossa sociedade uma associação do feminino à submissão e passividade. Logo, dos homens que adotam o papel ativo na relação sexual, espera-se uma postura máscula e uma performance viril. É preciso, porém, repensar a relação masculino/feminino a partir de uma díade entre ativo e passivo, e um passo possível em direção a tal transformação é dissociar a penetração do corpo da "efeminação". Um segundo passo atravessa a questão de que a posição assumida no sexo penetrativo não precisa, necessariamente, hierarquizar os parceiros em relação ao gênero (BRAZ, 2010).

Ademais, precisamos também pensar em modos de nos libertar dos rótulos e classificações em que nos aprisionamos, permitindo experimentar outros prazeres e nos amar de maneiras mais possíveis. Não nos referimos a um amor romântico, meramente, mas ao amor enquanto ato político, como 


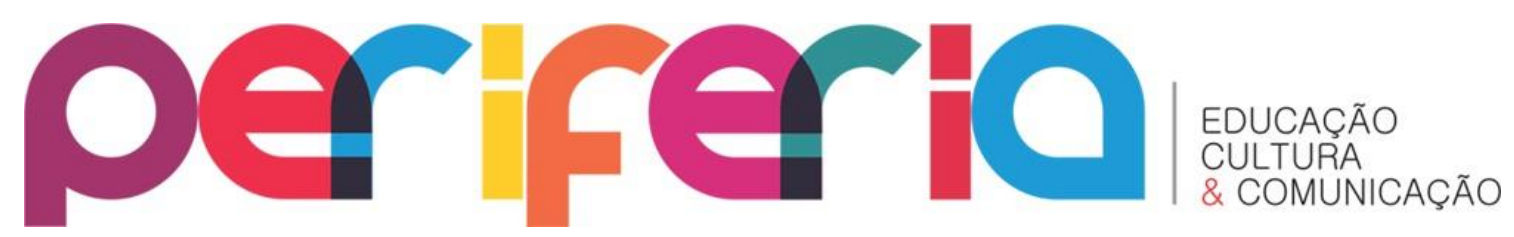

Hardt e Negri (2015) nos apontam, pensando em estados efetivos de democracia que não ponham em oposição anseios de maiorias contra minorias, mas integrem, interajam e unam os múltiplos presentes na multidão. Terminamos esta parte do texto com as palavras de Yuri Rosa, que afirma uma identidade afeminada provocante aos modos heteronormativos do ser/estar bicha:

Afeminados são a forma palpável do pleno. Sou gayzona mesmo, bicha, bichérrima, barbie, bambi, cor de rosa, porpurinada, andrógino, drag, cara no sol, sou Leo Áquila, Vera Verão, Giovana Melo, Michele Samer, Inês Brasil, sou diva, florzinha, delicadinha e tenho um quê de Carmen Miranda. E você, gay heteronormativo? (GAY, 2015).

\section{INTERNET, CONVERGÊNCIA E ATORES POLÍTICOS}

Os vídeos e o documentário sobre os quais nos debruçamos demonstram que produtores e consumidores de conteúdo não são mais ocupantes de papéis separados. Mesmo no caso do filme "Bichas, o documentário", uma produção que podemos chamar de profissionalizada, a disponibilização no YouTube, gratuitamente e com fácil acesso, revela uma mudança radical na distribuição da produção audiovisual, promovida pelo acesso à internet. No seu livro Cultura da convergência, Henry Jenkins (2009) propõe um conceito para definir as transformações tecnológicas, mercadológicas, culturais e sociais percebidas no cenário contemporâneo dos meios de comunicação. 0 autor analisa o fluxo de conteúdo que perpassa múltiplos suportes e mercados midiáticos, considerando o comportamento migratório percebido no público, e apresenta as mídias digitais como sendo ativas, participativas e interativas.

Ferreira lembra, em sua pesquisa sobre comunicação e relacionamento em redes sociais on-line, que "as convergências entre comunicação midiática, telecomunicação e novas tecnologias da informação estão entre os setores mais importantes e dinâmicos da sociedade capitalista" (FERREIRA, 2014, p. 19-20). As transformações que os "novos" paradigmas tecnológicos têm 


\section{periferio}

causado em nossa cultura, devidas à universalização de uma linguagem digital, comum a todos, que permite que a informação seja gerada, armazenada, recuperada, processada e transmitida, causam uma mudança fundamental em uma série de estruturas econômicas, sociais e culturais (CASTELLS, 2001).

Promovendo um diálogo com a Teoria da Cauda Longa, Vivian Belochio analisa o efeito dos inúmeros conteúdos disponíveis na internet, mesmo os que contam com uma relativa baixa audiência na comparação com os meios de comunicação tradicionais e com os hits da própria internet. Para a pesquisadora, no topo da curva da demanda ficam os produtos mais consumidos, os chamados hits, preferidos por grande parte da audiência. Mas há uma torção na soberania desses conteúdos, quando olhamos para o conjunto dos nichos presentes nas redes sociais on-line utilizando como referência uma Cauda Longa, que abarca uma ampla gama de novas fontes de dados na internet. Esses nichos eram antes estrangulados pelas limitações físicas e pela dificuldade de distribuição.

Em termos mais diretos, na era da comunicação digital é possível atender às necessidades e desejos de públicos específicos por meio das redes, que tem espaço ilimitado, abrigando, assim, tanto a preferência das massas quanto das minorias. [...] Acredita-se que o quadro atual configura uma cauda longa da informação (BELOCHIO, 2009, p. 3).

Somamos ao pensamento de Belochio a contribuição de Raquel Recuero (2004), que afirma que as redes possuem uma lógica de conexões preferenciais, não caracterizando formas randômicas ou igualitárias. Os novos nós da rede tendem a conectar-se com outros nós já estabelecidos, mais conectados, e sem a utilização de escalas, levando a um cenário de poucos nós com muitas conexões e muitos nós com poucas conexões. Nos interessam, para a compreensão do papel desempenhado pelos vídeos aqui analisados, os nós dessas redes sociais (as pessoas) e os laços sociais, cuja composição é definida pelos nós que unem os pares na relação grupal. 


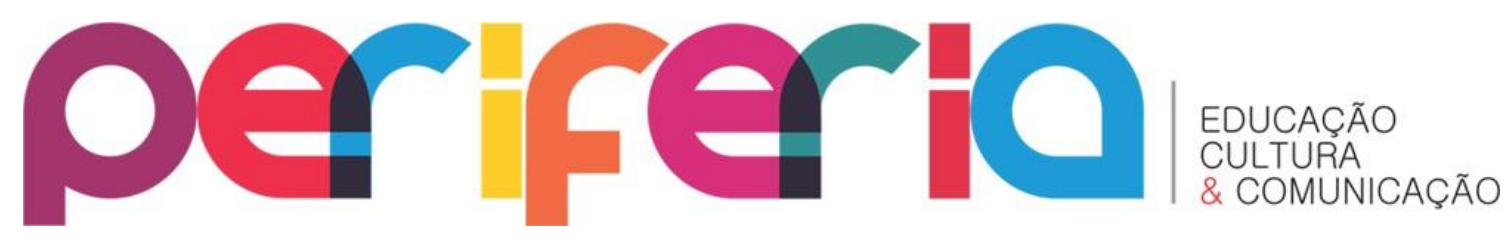

Articulando seus estudos com os as análises de Jenkins (2009), o professor Alex Primo reafirma que, mais do que a combinação de diversas funções midiáticas, a convergência deve ser pensada em termos culturais, como fluxo de conteúdos através de diferentes plataformas, com cooperação entre múltiplos mercados midiáticos, considerando que o público migra entre os meios de comunicação em busca das experiências e do entretenimento que deseja.

Alex Primo lembra que se, antes, a liberdade de expressão só existia para os donos dos jornais, agora, pessoas sem relação com as instituições midiáticas ganharam força de pressão coletiva e expressão pública por meio da internet. Primo traz à discussão a ideia de que o conceito de inteligência coletiva de Lévy (1998) poderia ser considerado como uma fonte alternativa de poder midiático, inspiração reconhecida por Jenkins. 0 espírito de época e o histórico de atritos com a hegemonia da indústria cultural, que orbitam em torno da criação da internet, fomentam esse processo de fortalecimento dos movimentos coletivos. "A internet criou tanto a cultura participativa quanto foi criada por ela" (PRIMO, 2010, p. 26).

Entretanto, Primo alerta para o fato de que essa nova realidade leva a uma sofisticação do poder do grande capital no contexto midiático. Os mercados de nicho, já abordados neste trabalho, deram um salto surpreendente, mas a hegemonia ainda está nas mãos da grande mídia. Parece haver uma maior interdependência, mas não "um jogo de soma zero, onde apenas um lado pode ganhar" (PRIMO, 2010, p. 30).

As análises que realizamos demonstram que esse jogo sem um vencedor único é jogado quando vídeos do YouTube ou do Vimeo e os conteúdos das diversas redes sociais online reverberam para além do ambiente da Internet e influenciam o agendamento dos meios de comunicação da grande mídia. Esse processo complexifica a formação da opinião pública. Foi isso que ocorreu com o documentário "Bichas" que ampliou a sua visibilidade ao chamar a 


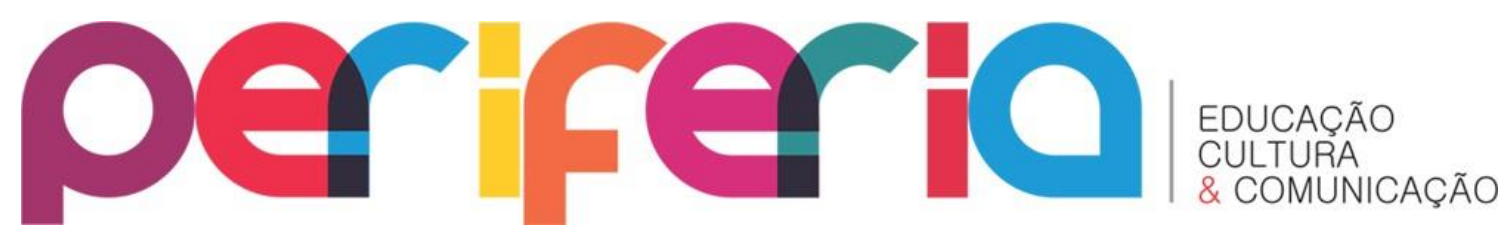

atenção da produção do programa "Amor e Sexo", líder absoluto no Ibope ${ }^{12}$ (KOGUT, 2017), da Rede Globo de Televisão, que convidou o diretor Marlon Parente para uma entrevista sobre o filme em rede nacional, no dia 2 de março de 2017, fazendo com que os desdobramentos da produção alcançassem uma dimensão para além da internet.

Sobre esse novo cenário da produção midiática, recorreremos aos estudos de Hjarvard (2013), que nos lembra que os meios de comunicação atuam como negociadores do consenso público. A disseminação das redes sociais possibilitou que um maior número de atores políticos interagisse mais diretamente uns com os outros. A proliferação dos meios digitais e interativos suplementa e complexifica o papel dos meios de comunicação na geração desse consenso público. A ascensão das novas mídias possibilitou que os atores políticos se inserissem no campo da produção e distribuição midiática. A partir daí, o processo de formação de opinião pública tornou-se mais complexo, pois possibilitou um maior número de atores políticos interagindo mais diretamente uns com os outros, cenário em que se encontram os vídeos e o documentário pesquisados neste trabalho.

\section{CONSIDERAÇÕES FINAIS: POR UMA REVOLUÇÃO PINTOSA}

Eu gostaria que existissem cada vez menos regras sociais para que a gente possa se aproximar mais das pessoas que são diferentes da gente. Isso só tem a acrescentar na nossa vida. Para você que é gay afeminado ou lésbica masculina: não se deixe sufocar, não caia na tentação de encenar um papel social que não cabe em você. Ser afeminado, bicha, bichona, bichérrima é parte fundamental para que as diferenças tenham visibilidade e causem mudanças concretas na sociedade. Ser diferente do padrão é revolucionário pelo

\footnotetext{
12 Pela metodologia do lbope, cada ponto de audiência equivale a $1 \%$ do universo pesquisado em cada praça aferida. Na Grande São Paulo, 1 ponto equivale a 70,5 mil domicílios e 688,2 mil indivíduos. No Grande Rio de Janeiro, 1 ponto representa 44,05 mil lares e 116,9 mil pessoas. 0 instituto monitora a audiência de televisão em 15 regiões do país. Nacionalmente, cada 1 ponto de audiência corresponde a 245.702 domicílios e a 688.211 espectadores. Fonte: G1 <http://g1.globo.com/economia/midia-emarketing/noticia/kantar-ibope-atualiza-representatividade-de-cada-ponto-de-audiencia-de-tv.ghtml> Acesso em: 29 mai. 2017.
} 


\section{periferio}

simples gesto de ser quem você é. Se orgulhe disso (GAYS, 2015).

O bordão "isso é uma bichona" não é para menos: tratava-se de mais um modo sutil de fascismo, que inferioriza a homossexualidade, colocando, principalmente, a efeminação como algo pejorativo e abjeto. Tal quadro reafirmava que "ser, gay tudo bem, mas não precisa ficar dando pinta por aí". Apesar disso, e por mais que ainda seja perceptível o preconceito em relação às afeminadas, empurradas involuntariamente para um lugar marginal, podemos encontrar também algumas formas de resistência e de questionamento ao lugar ocupado pela bicha em nossa sociedade, como mostram nossas interlocutoras ao longo deste texto. Interessa-nos observar como elas estão colocando "a cara no sol", afirmando uma verdadeira "revolução pintosa" que produz, por exemplo, vídeos que contestam e deslocam as normas vigentes da sexualidade. João Pedro Carneiro, em entrevista ao documentário Bichas, afirma:

Depois que eu comecei a dizer assim: porra, eu sou bicha! Todo mundo me chama de bicha mesmo. Sou bicha, tá ligado? E vai ser isso mesmo. Vai ser isso que eu sou. Eu sempre vou ser bicha. Eu vou morrer bicha. Todo dia mais bicha. Todo dia um level a mais, igual a Pokémon [...] Se a gente não mostrar e ficarem pressionando pra gente não ser bicha, eles vencem. $E$, querida, quem vai ganhar é a bicha! Certeza! (BICHAS, 2016).

As imagens em movimento corroboram para o engendramento de concepções de sujeito, de gênero, sexualidade e normalidade, e, dessa forma, produzem visões de mundo diversas nos mais diferentes contextos de realidades e sociedades. Nas palavras de Guacira Lopes Louro (2008), os filmes atuam como uma pedagogia cultural, ensinando e aprendendo modos de existir que nunca havíamos pensado. Certamente, muitas concepções produzidas em nossa cultura têm como referência as significações que emergem das relações entre o sujeito e as imagens cinematográficas. Esses vídeos são modos de realizar também uma pedagogia cultural que subverte a 


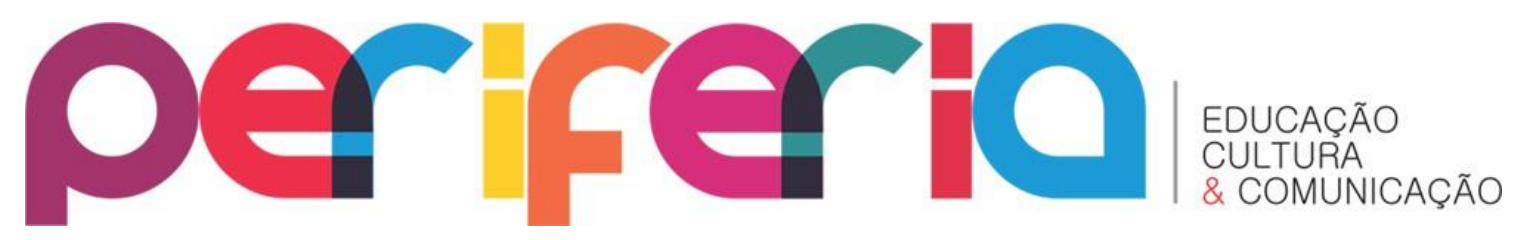

ordem hegemônica, produzindo outros modos de subjetivação e inteligibilidade cultural. Espalhando-se nas mídias alternativas e atingindo até mesmo a grande mídia, produzem rachaduras nas concepções universalizantes das sexualidades e gêneros.

Foucault nos ensina que onde há poder, há resistência - assim como o poder opera por uma lógica de pulverização, "não existe propriamente o lugar da resistência, mas pontos móveis e transitórios que também se distribuem por toda a estrutura social” (FOUCAULT, 2006, p. 14). Nesse sentido, é importante questionar por que consideramos tão ofensivo ser ou parecer uma mulher, nas relações estabelecidas entre as bichas, e por que aquilo que é ligado ao feminino precisa ser minimizado na construção dos corpos, das identidades e dos existires gays.

Para que seja possível construir outros modos de relação, que, ao contrário de buscar a homogeneização, afirmem e celebrem a heterogênese, é necessário transformar radicalmente o modelo de dominação masculinista, inclusive o ideal de masculinidade hegemônica e a heteronormatividade afirmados pelas próprias bichas. Além disso, é necessário insistir na dissociação entre sexo-gênero-desejo, para abrir frente a outras múltiplas e complexas articulações. Enfim, o que temos que buscar é respeitar e vivercom as diferentes formas de existência, para além de jogos de poder, quadros de guerra, pazes veladas ou guerras silenciosas.

\section{REFERÊNCIAS}

BADINTER, E. XY, de l'identité masculine. Paris: LGVF, 1994.

BARBIE. In: Dicionário informal. Disponível em: <http://www.dicionarioinformal.com.br/barbie>. Acesso em: 18 jan. 2016.

BEAR. In: Dicionário informal. Disponível em: <http://www.dicionarioinformal.com.br/bear>. Acesso em: 18 jan. 2016.

BICHA, a senhora é destruidora mesmo, viu. Disponível em: $<$ https: / /www.youtube.com/ watch? v=h2JR_obBUZk $>$. Acesso em: $11 \mathrm{dez}$. 2015. 


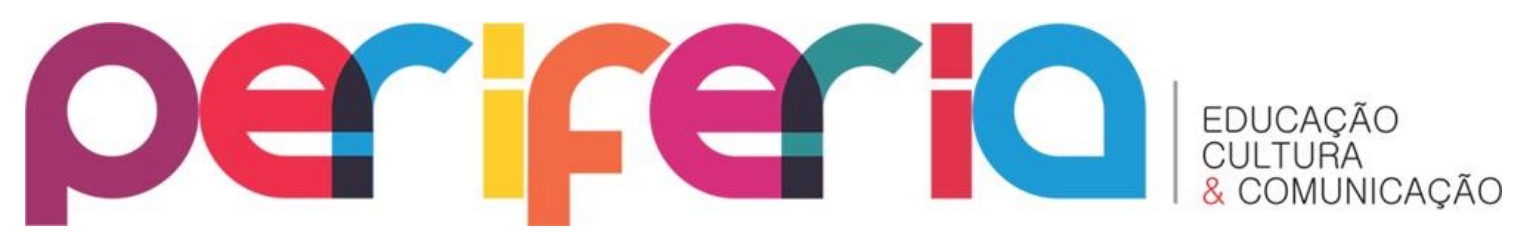

BICHAS, o documentário. Direção: Marlon Parente. 39 min, color. Disponível em: <https: / /www.youtube.com/watch?v=0cik7j-0cVU>. Acesso em: 14 mai. 2017.

BOURDIEU, P. La dominación masculina. Barcelona: Anagrama, 2000.

BRAZ, C. A. À meia luz... Uma etnografia imprópria em clubes de sexo masculinos. 2010. Tese (Doutorado) - Universidade Estadual de Campinas, Instituto de Filosofia e Ciências Humanas. Campinas, 2010.

BUTLER, J. Quadros de guerra: quando a vida é passível de luto? Rio de Janeiro: Civilização Brasileira, 2015.

. Problemas de gênero: feminismo e subversão de identidade. Rio de Janeiro: Civilização Brasileira, 2003.

. Imitation and Gender Insubordination. In: ABELOVE, H.; BARALE, M. A.; ALPERIN, D. M. (Orgs.). The lesbian and gay studies reader. Nova lorque: Routledge, 1993. p. 307-320.

CACURA. In: Dicionário informal. Disponível em: <http://www.dicionarioinformal.com.br/cacura . Acesso em: 18 jan. 2016.

CASTELLS, M. A sociedade em rede. São Paulo: Paz e Terra, 2001.

COLLING, L.; NOGUEIRA, G. Relacionados mas diferentes: sobre os conceitos de homofobia, heterossexualidade compulsória e heteronormatividade. In: RODRIGUES, A.; DALLAPICULA, C.; FERREIRA, S. R. da S. (Orgs.).

Transposições: lugares e fronteiras em Sexualidade e Educação. Vitória: EDUFES, 2014.

DE HANNAH Montana à Miley Cyrus: a transformação. Portal Terra. 25 fev. 2016. Disponível em:

<https://www.terra.com.br/diversao/musica/baladice/de-hannah-montanaa-miley-cyrus-a-

transformacao,e92afc53ccdaa3b8e5b4160d8ea89f62b8bvnqfm.html >. Acesso em: 26 mai. 2017.

FACCHINI, R. Movimento homossexual no Brasil: Recompondo um histórico. Cadernos AEL, v. 10, n. 18/19, 2003.

FOUCAULT, M. Microfísica do poder. 22. Ed. Rio de Janeiro: Graal, 2006.

FRY, P. Para inglês ver: identidade e política na cultura brasileira. Rio de Janeiro: Zahar, 1982. 


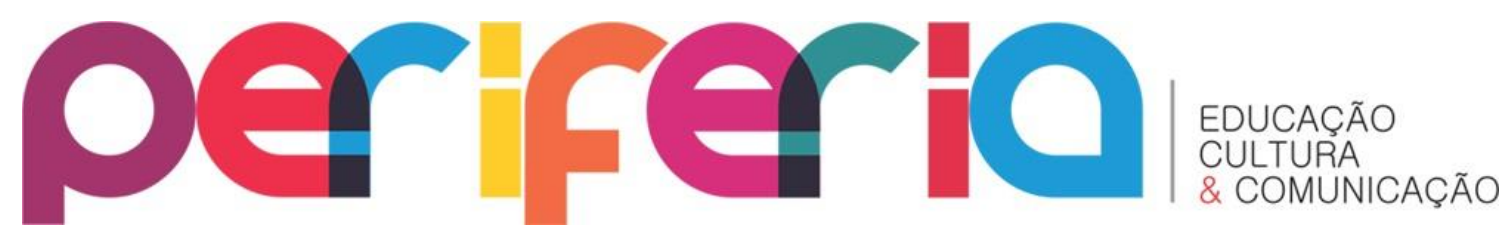

GAY, afeminado e orgulhoso. Compartilhem essa ideia! Yuri Rosa. Disponível em: <https: / /www.facebook.com/MozieFleur/videos/774592922648427>. Acesso em: 16 de janeiro de 2016.

GAYS afeminados. Lorelay Fox. Canal Para Tudo. Disponível em: <https://www.youtube.com/watch?v=nSfuXJcbN4Y>. Acesso em: 16 jan. 2016.

HALL, S. A identidade cultural na pós-modernidade. Rio de Janeiro, DP\&A, 2003.

HARDT, M.; NEGRI, A. Multidão: guerra e democracia na era do império. Rio de Janeiro: Record, 2005.

HJARVARD, S. A Midiatização da Cultura e da Sociedade. São Leopoldo: Unisinos, 2013.

JENKINS, H. Cultura da Convergência: a colisão entre os velhos e novos meios de comunicação. São Paulo: Aleph, 2009.

LÉVY, P. A inteligência coletiva: por uma antropologia do ciberespaço. São Paulo: Loyola, 1998.

LOURAU, R. Pequeno Manual de Análise Institucional. In: ALTOÉ, S. (Org.). René Lourau: analista institucional em tempo integral. São Paulo: Hucitec, 2004. p. 122-127.

LOURO, G. L. Cinema e Sexualidade. Revista Educação \& Realidade, v.33, n. 1, p. 81-98, jan./jun., 2008.

. Corpo estranho: ensaios sobre sexualidade e teoria queer. Belo

Horizonte: Autêntica, 2004.

MAIS afeminada do grupo. Disponível em:

<https: / /www.youtube.com/watch?v=s_Ey7mi20v0>. Acesso em: 17 jan. 2016.

KANTAR Ibope atualiza representatividade de cada ponto de audiência de TV. G1. Rio de Janeiro, 4 jan. 2017. Disponível em: <http://g1.globo.com/economia/midia-e-marketing/noticia/kantar-ibopeatualiza-representatividade-de-cada-ponto-de-audiencia-de-tv.ghtml > . Acesso em: 29 mai. 2017.

KOGUT, Patrícia. “'Amor \& sexo' tem melhor estreia desde 2011 em São Paulo e 2012 no Rio”. O Globo, Rio de Janeiro, 27 jan. 2017. Disponível em:

<http://kogut.oglobo.globo.com/noticias-da-

tv/audiencia/noticia/2017/01/amor-sexo-tem-melhor-estreia-desde-2011-emsao-paulo-e-2012-no-rio.html>. Acesso em: 15 mai. 2017. 


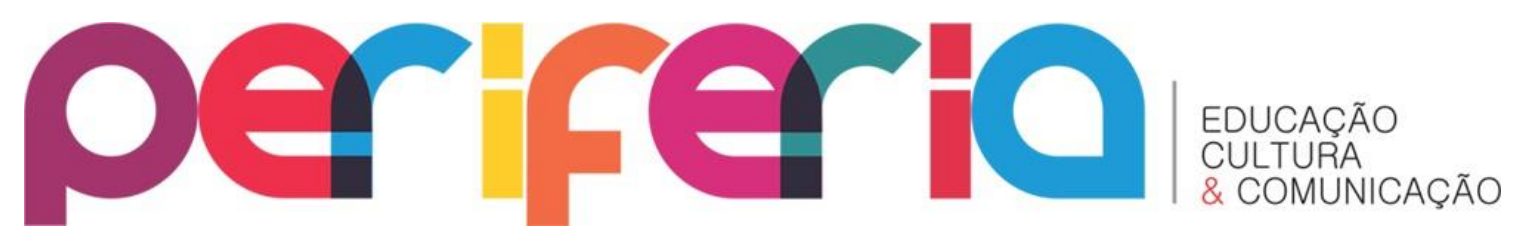

LÁZARO, 22. Lázaro dos Anjos Moreira. Disponível em:

<https://vimeo.com/134985722>. Acesso em: 16 jan. 2016.

MACRAE, E. Os respeitáveis militantes e as bichas loucas. In: COLLING, L. (Org.). Stonewall 40 + o que no Brasil? Salvador: EDUFBA, 2011.

MANTEGA, G. Sexo e poder. São Paulo: Brasiliense, 1979.

MARTORY, N. Põe a cara no sol, mona! Disponível em:

<https://www.youtube.com/ watch?v=kvlkULPtIOk>. Acesso em: $11 \mathrm{dez} .2015$.

MISKOLCI, R. Teoria queer: um aprendizado pelas diferenças. Belo Horizonte: Autêntica, 2012.

PERLONGHER, N. O desaparecimento da homossexualidade. In: LANCETTI, A. Saúde Loucura. São Paulo: Hucitec, 1993.

PINTOSA. In: Dicionário informal. Disponível em:

<http://www.dicionarioinformal.com.br/pintosa $>$. Acesso em: 18 jan. 2016.

PRECIADO, P. B. Multidões queer: notas para uma política dos anormais.

Estudos Feministas, Florianópolis, ano 19, n .1, 2011, p. 11-20.

PRIMO, A. A produção social da identidade e da diferença. In. SILVA, T. T. da (org). Identidade e diferença: a perspectiva dos estudos culturais. Petrópolis: Vozes, 2014, p. 73-102.

PRIMO, A. Crítica da cultura da convergência: participação ou cooptação. In: DUARTE, E. B.; CASTRO, M. L. D. de C. (Org.). Convergências Midiáticas: produção ficcional - RBS TV. Porto Alegre: Sulina, 2010, p. 21-32.

RECUERO, R.. Teoria das redes e redes sociais na Internet: Considerações sobre o Orkut, os Weblogs e os Fotologs. XXVII Intercom, 2004, Porto Alegre. Anais do XXVII Intercom, 2004.

SHELLEY, M. Frankenstein ou o Prometeu moderno. São Paulo: Martin Claret, 2012.

WOODWARD, K. Identidade e diferença: uma introdução teórica e conceitual. In. SILVA, T. T. da (org). Idendidade e diferença: a perspectiva dos estudos culturais. Petrópolis: Vozes, 2014, p. 7-72

ZAMORA, M. H.. Os corpos da vida nua: sobreviventes ou resistentes? Latin America Jornal of Fundamental Psychopath. São Paulo, v.5, n. 1, p. 104-117, 2008. 


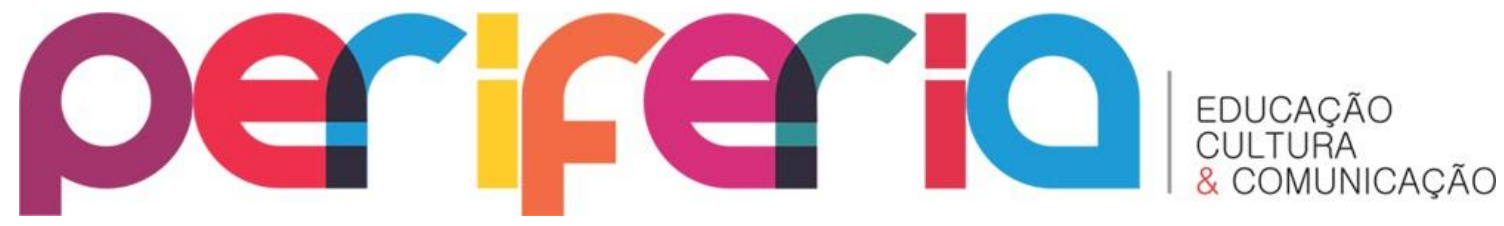

ZORRA TOTAL Severino quebra-galho. Disponível em:

<https: / / www.youtube.com/ watch?v=9R_3YON9LOY >. Acesso em: 17 jan. 2016. 